\title{
Use of Tropical Vancomycin in Decreasing the Incidence of Surgical Site Infection in Patients Undergoing Open Heart Surgery
}

\author{
MUHAMMAD MOHSIN MAHMOOD ${ }^{1}$, AQEEL AHMAD², WASEEM REHMAN ${ }^{3}$ \\ ${ }^{1,3}$ Registrars, ${ }^{2}$ Associate Professor, Department of Cardiothoracic Surgery, Shaikh Zayed Hospital, Lahore \\ Correspondence to Dr. Muhammad Mohsin Mahmood E-mail: drmmm62@gmail.com Cell: 0333-9778331
}

\begin{abstract}
Aim: To study the effect of vancomycin tropically in decreasing the incidence of sternal wound infection in patients undergoing open cardiac surgery.

Study design: Randomized controlled trial

Place and duration: Department of Cardiovascular \& Thoracic Surgery Sheikh Zayed Hospital Lahore from $1^{\text {st }}$ January 2019 to $31^{\text {st }}$ July 2020.

Methods: A total of 180 male and female planned for elective open heart surgery is selected for this research work. All patients age is between 40 and 70 years and these patients are bifurcated in two groups. In Group I there are 90 patients in which vancomycin is used on the sternal edges, while in Group II there are 90 patients in which only normal saline wash is used at the time of sternal approximation. At the end incidence of sternal wound infection is monitored to establish the benefits of tropical vancomycin.

Results: One hundred and thirty three $(73.89 \%)$ were males and $47(26.11 \%)$ were females. Topical vancomycin group has decreased rate of superficial and deep sternal wound infections as compared to the patients in which topical vancomycin is not applied (2.22\% vs $6.67 \%)$ and $(1.11 \%$ vs $4.4 \%)$.

Conclusion: Application of vancomycin tropically at surgical site at the time of closure of sternum in conjunction with prophylactic use of antibiotics reduces wound infection in open heart surgery.

Keywords: Open heart surgery, Vancomycin, Sternal wound infection
\end{abstract}

\section{INTRODUCTION}

Open heart surgery is a clean procedure with a possibility of infection postoperatively. Median sternotomy is the basic procedure in cardiac surgery. There is $0.5 \%$ to $8.0 \%$ sternal wound infections (SWIs) in open heart surgery postoperatively associated with high morbidity, mortality and stay in hospital with high cost effect. The uses of wide spectrum antibiotics prophylectly in perioperative or postoperative period never prevent infection in all cases. ${ }^{1}$

In open heart surgery the risk factors of surgical site infection vary according to type of surgical procedure. The predictive factors of surgical site infection in patient characteristics are identified such as diabetes mellitus, COPD, emergency/urgency or prolonged procedures and Obesity. $^{2}$

Now a day's increase in population size anticipated that rise in the prevalence of these comorbidities leads to rise in potentially devastating problems. The improvement in the rates of surgical site infection after sternotomy has not yet achieved even after different preventive measures are adopted and different population based studies carried out. $^{3}$

Advancements in the techniques of open heart surgery has led to development of new measures to reduce complications regarding surgical site infections. The use of topical antibiotics par operatively is the main field of interest now a days in the whole world by utilizing different ingredients like vancomycin, gentamycin and cefazolin along the edges of sternum before closure of sternum with steel wires. ${ }^{4}$ The non-systemic topical use of these

Received on 17-12-2020

Accepted on 03-04-2021 ingredients shows good results in trials to reduce the sternal wound infection postoperatively. ${ }^{5}$

The use of vancomycin intravenously in open heart surgery is a routine practice but many cardiac surgeons additionally use topically over sternal edges. ${ }^{6}$

Only limited work is available to date which is going to prove the use of vancomycin on sternal edges to decrease the prevalence of sternal infections after open heart surgery. In the present study, hypothesis is the use of topical vancomycin reduces sternal wound infection postoperatively. This clinical trial is carried out at the Unit of Cardiovascular and Thoracic Surgery Shaikh Zayed Hospital Lahore to prove the efficacy of vancomycin in decreasing surgical site infection after open heart surgery.

\section{MATERIALS AND METHODS}

This randomized controlled trial is conducted at Department of Cardiac Surgery Shaikh Zayed Hospital Lahore from $1^{\text {st }}$ January 2019 to $31^{\text {st }}$ July 2020. All male and female patients between 40-70 years undergoing cardiac surgery were included. All patients undergoing redo cardiac surgeries, allergic to vancomycin, renal failure, having pre-operative high TLC count and not giving consent were excluded. A total of 180 patients of both genders who underwent open heart surgery are selected for study. The detailed medical history including age, sex, history of previous cardiac surgery, diabetes mellitus, smoking history, hypertension, are examined after taking informed consent from all the patients. In every selected patient for study prophylactic antibiotics are given at the time of induction which includes injection ceftrioxone $(1 \mathrm{~g})$ and co-amoxiclav $(1.2 \mathrm{~g})$. This regime of antibiotics combination is continued IV for 72 hours postoperatively. In diabetic patients Injection insulin regular is used according 
to blood glucose levels to keep it within normal limits. All patients are planned in two groups; Group I consist of 90male and female individuals injection vancomycin powder (1gm) is applied on sternal edges and Group II consist of 90 patients in which only normal saline wash is used at the time of surgical site closure. We followed-up the patients for six weeks and occurrence of superficial and deep surgical site infection is noted. Other considerable factors that can contribute in surgical site infections likepoor glycemic control, cigarette or any other drug addiction, increased time of operation, time of aortic cross clamping and total bypass time are also carefully noted along with usage of tropical vancomycin. All the statistical data was analyzed by SPSS-20. P-value $<0.05$ is considered as significant.

\section{RESULTS}

In group I, $70(77.78 \%)$ patients were males and 20 (22.22\%) patients were females while in group II, 63 (70\%) patients were males and 27 (30\%) patients were females. Thirty four patients belonged to age group $<50,42$ are between $50-60$ years and 14 patients are $>60$ years old in group I whereas in group II, 30 patients are $<50$ years, 44 patients were between $50-60$ and 16 patients are $>60$ years of age. In group 1, $26(28.89 \%)$ are hypertensive while in group II 29 (32.22\%) patients has this comorbidity. The incidence of diabetes was higher in group 1, $18(20 \%) \mathrm{v} / \mathrm{s}$ $10(11.1 \%)$. There were $20(22.22 \%)$ smokers in group I as compare to 14 (15.55\%) Group II. We found no significant difference according to age, sex, BMl except diabetes mellitus and smoking (Table 1).

All individuals in which topical vancomycin is applied has reduced incidence of superficial and deep surgical site infections as compared to the patients in which normal saline is used (superficial infections:1.11\% v/s $8.89 \%$ ), (deep wound infections:1.11\% v/s 6.67\%).These results shows significant incidence of surgical site infection in both groups $(P<0.05)$. The mean bypass time in Group I and Group II is $114.7 \pm 48.5$ and $122.6 \pm 40.2$ minutes, statistically no significant difference is recorded $(P>0.05)$. Cross clamp time in Group I and Group II is 64.4 \pm 31.5 and 74.7 \pm 30.2 minutes respectively.

Table 1:Preoperative data.

\begin{tabular}{|c|c|c|c|}
\hline Data & Group I & Group II & P-value \\
\hline \multicolumn{4}{|l|}{ Gender } \\
\hline Male & $70(77.78 \%)$ & $63(70 \%)$ & \multirow{2}{*}{0.53} \\
\hline Female & $20(22.22 \%)$ & $27(30 \%)$ & \\
\hline \multicolumn{4}{|l|}{ Age (years) } \\
\hline$<50$ & $34(37.78 \%)$ & $30(33.33 \%)$ & \multirow{3}{*}{0.41} \\
\hline $50-60$ & $42(46.67 \%)$ & $44(48.89 \%)$ & \\
\hline$>60$ & $14(15.55 \%)$ & $16(17.78 \%)$ & \\
\hline Body mass index & $25.6 \pm 5.9$ & $26.2 \pm 5.7$ & 0.68 \\
\hline Hypertension & $26(28.89 \%)$ & $29(32.22 \%)$ & 0.6 \\
\hline Diabetes mellitus & $18(20 \%)$ & $10(11.11)$ & 0.05 \\
\hline Smokers & $20(22.22 \%)$ & $14(15.55 \%)$ & 0.32 \\
\hline
\end{tabular}

Table 2: Post-operative incidence of sternal wound infections

\begin{tabular}{|c|c|c|c|}
\hline Variable & Group I & Group II & P-value \\
\hline \multicolumn{4}{|l|}{ Infections } \\
\hline Superficial & $1(1.11 \%)$ & $8(8.89 \%)$ & 0.001 \\
\hline Deep Sternal & $1(1.11 \%)$ & $6(6.67 \%)$ & 0.000 \\
\hline Total incidence & $2(2.22 \%)$ & $14(15.56 \%)$ & 0.000 \\
\hline \multicolumn{4}{|l|}{ Diabetic Patients } \\
\hline All sternal infections & $0(0.0 \%)$ & $3(3.33 \%)$ & 0.000 \\
\hline Mean bypass time (min) & $114.7 \pm 48.5$ & $122.6 \pm 40.2$ & 0.000 \\
\hline Cross clamp time (min) & $64.4 \pm 31.5$ & $74.7 \pm 30.2$ & 0.000 \\
\hline
\end{tabular}

\section{DISCUSSION}

Open heart surgery through median sternotomy is a standard technique worldwide. Our results have shown that by the use of topical vancomycin and antibiotics peri- and post-operatively with good glycemic control the rate of superficial and deep surgical site infections is very low. Tropical antibiotics, either used in paste or powder form, have very high concentration locally than systemically used and persist for longer duration.

In a randomized, prospective, blinded trail in 416 patients of Vander Salm and colleagues ${ }^{6}$ resulted that sternal wound infection incidence in open heart surgery is reduced from $3.6 \%$ to $0.45 \% \quad(P=0.02)$ with the use of topical vancomycin combined with systemic antibiotics peri and post-operatively.

Another retrospective study of 1020 patients carried out by Arruda and colleagues ${ }^{7}$ have shown that with the use of vancomycin on sternal edges the occurrence of surgical sitewound infections is reduced to $0.49 \%$.

Ozzan and colleagues ${ }^{8}$ studied effect of topical vancomycin in rats. In this model methicillin-resistant Staphylococcus aureus injected in rat's sternum. There is significant reduction in the number of microorganisms after one week in the bones of those animals who received a combination of both topical and systemic antibiotics as compared to those who received only $\mathrm{i} / \mathrm{v}$ antibiotics systemically.

Now a day the development of antibiotic resistance is a major apprehension in medical field. There is high suspicion that application of vancomycinon sternal edges may results in resistance strains of microorganisms due to increased levels of this drug in the blood. ${ }^{9}$ In order to evaluate the effects of vancomycin applied on sternal edges its levels are measured on zero post-operative day and on $6^{\text {th }}$ post-operative day. A noteworthy decline in the serum levels of vancomycin is noted which ranges $11.5 \pm 1.9$ $\mathrm{mg} / \mathrm{mL}$ to $2.12 \pm 0.19 \mu \mathrm{g} / \mathrm{mL}(P<0.0001)$ with zero surgical site infection. Moreover there was no toxic effect postoperatively on renal profile by use of vancomycin at sternal edges and ithas no resistant strains in 1year follow up $^{10}$.

The concept regarding beneficial effect of vancomycin applied directly on the sternum is most likely because it potentiates union of the sternal bone as well as increase 
the healing of the surgical site by decreasing the colonization of bacteria. We did not find any unstable sternum or any malunion of the bone in individuals who get application of vancomycin at sternal edges, even those patientswho are known diabetics. There is similarity in the mechanism of action with gelatin-thrombin sealant that promotes fibroblast growth by acting as an osteoinductive protein. ${ }^{11}$ Sternal nonunion and osteomyelitis major risks in open heart surgery have been reduced by stimulating bone formation by providing matrix for translocation of osteoblast by osteoinductive protein. ${ }^{12}$

In addition, use of tropical vancomycin reducing the growth of bacteria and bacterial inoculation of bone. Many other surgical fields like neurosurgery ${ }^{13}$; dental implants ${ }^{14}$ and embedding of left ventricular assist devices ${ }^{15}$ have also shown good results in reducing the surgical site infection. Other benefits of topical vancomycin are safe to handle, comparatively low cost with no major side effects locally and systemically. Another beneficial effect of topical vancomycin is its hemostatic effect by adhering to sternal edges as well as bacteriostatic and bacteriocidal effects on gram-positive microorganisms such as Staphylococcus and Streptococcus.

The limitations of this prospective study include relatively small sample size with same peri and postoperative protocols followed for antibiotics and operative techniques and post-operative care during study and it is a single center study. More randomized prospective studies are need of the hour to be conducted in high risk population undergoing open heart surgery especially in patients with renal insufficiency, earlier to make it standard for usage of tropical vancomycin in reduction of surgical site infections.

\section{CONCLUSION}

The surgical site infection is a leading postoperative complication in open heart surgery which could be a nightmare for surgeons. We concluded that use of tropical vancomycin over sternal edges decreases surgical site infection and improves morbidity and mortality of patients and it is very cost effective.

\section{REFERENCES}

1. Perviaz F, Chaudhry IA, Javaid R, Khalil H, Kamran J, Khattak F, et al. Topical vancomycin in cardiac surgery to reduce sternal wound infections: a randomized controlled trial at a tertiary cardiac care facility. J Surg Surg Res 2019;5(1):15-8.
2. Meszaros K, Fuehrer U, Grogg S. Risk factors for sternal wound infection after open heart operations vary according to type of operation. Ann Thorac Surg 2016; 101(4): 1418-25.

3. Edmiston CE, Spencer M, Lewis BD (2011) Reducing the risk of surgical site infections: did we really think SCIP was going to lead us to the promised land? Surg Infect 2011; 12(3): 16977.

4. Lazar HL, Barlam $\mathrm{T}$, Cabral $\mathrm{H}$. The effect of topical vancomycin applied to sternotomy incisions on postoperative serum vancomycin levels. J Card Surg 2011; 26(5), 461-465

5. Lazar HL, Ketchedjian A, Haime M, Karlson K, Cabral H. Topical vancomycin in combination with perioperative antibiotics and tight glycemic control helps to eliminate sternal wound infections. J Thorac Cardiovasc Surg 2014; 148(3): 1035-40.

6. Vander Salm TJ, Okike ON, Pasque MK, Pezzella AT, Lew R, et al. Reduction of sternal infection by application of topical vancomycin. J Thorac Cardiovasc Surg 1989; 98(4): 618-22.

7. Arruda M, Braile D, Joaquim M, Suzuki F, Alves R. The use of the vancomycin paste for sternal hemostasis and mediastinitis prophylaxis. Rev Bras Cir Cardiovasc 2008; 23(1): 35-9.

8. Ozcan AV, Demir M, Onem G, Goksin I, Baltalarli A, Topkara VK, et al. Topical versus systemic vancomycin for deep sternal wound infection caused by methicillin-resistant Staphylococcus aureus in a rodent experimental model. Tex Heart Inst J 2008; 33(2): 107-10.

9. Smith TL, Pearson ML, Wilcox KR, Cruz C, Lancaster MV, Robinson-Dunn B, et al. Emergence of vancomycin resistance in Staphylococcus aureus. GlycopeptideIntermediate Staphylococcus aureus Working Group. N Engl J Med 1999; 340(7): 493-501

10. Lazar HL, Barlam T, Cabral H. The effect of topical vancomycin applied to sternotomy incisions on postoperative serum vancomycin levels. J Card Surg (2011; 26(5): 461-5.

11. Abiraman S, Varma HK, Umashankar PR, John A. Fibrin glue as an osteoinductive protein in a mouse model. Biomaterials 2002; 23(14): 3023-303

12. Zhang L, Wang P, Mei S, Li C, Cai C, Ding Y. In vivo alveolar bone regeneration by bone marrow stem cells/fibrin glue composition. Arch Oral Biol 2012; 57(3): 238-44.

13. Chiang HY, Herwaldt L, Schweizer M. Effectiveness of local vancomycin powder to decrease surgical site infections: a meta-analysis. Spine J 2014; 14(3): 397-407.

14. Molinari RW, Khera OA, Molinari WJ $3^{\text {rd }}$. Prophylactic intraoperative powdered vancomycin and postoperative deep spinal wound infection: 1,512 consecutive surgical cases over a 6-year period. Eur Spine J 2012; 21(4): 476-82.

15. Morgan A, John R, Rao V, Weinberg AD, Lee BJ, Mazzeo $P A$, et al. Bridging to transplant with the Heart Mate left ventricular assist device: the Columbia Presbyterian 12-year experience. J Thorac Cardiovasc Surg 2004; 127(5): 130916. 